\title{
Intimate Partner Violence: Thailand Situation and Intervention Programme
}

\author{
Montakarn Chuemchit and Usaneya Perngparn, Member, IEDRC
}

\begin{abstract}
Intimate partner violence is a significant public health problem issues in Thai society. The objectives of this study were: 1) To explore severed cases of Bangkok women who came to the hospital from physical, psychological and sexual violence by their partner 2) To understand circumstances of intimate partner violence and health consequences 3) To develop model intervention for reduction of intimate partner violence problem. This study deployed two research studies to collect data; Quantitative data collection and Qualitative method. The quantitative study findings showed that more than $60 \%$ of perpetrators were married couples/cohabiting. More than $50 \%$ of women were re-victimization. The qualitative study findings revealed that several factors were found to be associated with intimate partner violence, for instance, alcohol or drug abuse $(n=15)$, lack of emotional control $(n=10)$, family relations and communication $(n=20)$. Consequences of intimate partner violence have been linked to many immediate and long-term health outcomes. From those data were developed intervention programme to reduce intimate partner violence. Intervention to identify victims of intimate partner violence and prevent batterers from continuing to use violence as well as provide effective care and support will reduce and breaking cycles of violence from one generation to the next.
\end{abstract}

Index Terms-Intimate partner violence, intervention programme, Thailand.

\section{INTRODUCTION}

Violence against women is a danger facing women in every corner of the world. One in 5 of women in the world have experienced some act of physical violence. Every minute woman has been raped 1.3 persons [1].

The United Nation defines violence against women as any act of gender based violence that results in, or is likely to result in, physical, sexual or mental harm or suffering to women, including threats of such acts, coercion or arbitrary deprivation of liberty, whether occurring in public or in private life [2]. There are many forms of violence against women. One of the most common forms is intimate partner violence or domestic violence [3].

Intimate partner violence or domestic violence often took place in the home. The perpetrator can be the women's husband, ex-husband, or lover. Intimate partner violence takes many forms : physical violence by means of punching, kicking, stomping, use of weapons to cause injuries, and killing; sexual violence through rape or forced unwanted sex

Manuscript received August 18, 2013; October 23, 2013. This work was partially-supported by The $90^{\text {th }}$ Anniversary of Chulalongkorn University Fund (Ratchadaphiseksomphot Endowment Fund).

Montakarn Chuemchit is with the College of Public Health Sciences, Chulalongkorn University, Bangkok, 10330 Thailand (e-mail: montakarn.ch@chula.ac.th). acts; and psychological violence by tormenting, verbal assault, threats, locking up, use of social and economic means to torment, refusal to provide financial support, or verbal degrading [4].

Intimate partner violence is increasingly seen as an important public health problem [3].It has been estimated that worldwide approximately 8.7 million women are victimized by current or former intimate partner each year [5]. In 48 population-based surveys from around the world, 10-69\% of women reported being physically assaulted by an intimate male partner at some point in their lives [3].

In Thailand, from the report of 2006 Reproductive Health Survey designated that married women aged 15-49 years about 12,000,000 persons had ever assault or mind in the whole country [6]. The study of Archavanitkul et al showed that $44 \%$ of Thai women have experienced some act of violence by husband. $29 \%$ of Thai women have experienced some act of physical violence. $30 \%$ of Thai women have experienced some act of sexual violence [4].

Violence by an intimate partner has been linked to many immediate and long-term health outcomes [3]. It can impact significantly on woman's physical, emotional, and mental health through depression and suicidal behaviour [7]. Partner violence also affects reproductive health and can lead to gynecological disorders, unwanted pregnancy, premature labor and birth, as well as sexually transmitted diseases and HIV/AIDS [3]. These negative effects can be long lasting [8]. Intervention to identify victims of IPV and provide effective care and support will help for protecting health, increase victims' safety behaviours, reduce further harm, and breaking cycles of violence from one generation to the next, however, most of IPV violence intervention/programme is currently limited in two respects: first, most of it comes from the United States and other developed countries and, second, there is insufficient research on the long-term effects of such interventions [9].

This study examined severed cases of Bangkok women who came to the hospital from physical, psychological and sexual violence by their partner .Explored to understand circumstances of intimate partner violence and health consequences by in-depth interview 20 cases. This study will also offer intervention programme for reduction of intimate partner violence problem

The objectives of this study were: 1) To explore severed cases of Bangkok women who came to the hospital from physical, psychological and sexual violence by their partner 2) To understand circumstances of intimate partner violence and health consequences 3) To develop model intervention for reduction of intimate partner violence problem. 


\section{Procedure FOR PAPER SUbMission}

\section{A. Design}

This study deployed two research studies to collect data. Quantitative data collection from patient record between July - December, 2010 from one stop crisis centre (OSCC) in 3 hospitals of Bangkok Metropolitan Administration which covered areas in city and out city of Bangkok; to explore severed cases of abused women. Qualitative method by in-depth interviews 20 cases; 10 victims and 10 perpetrators as well as literature review; to understand circumstances of intimate partner violence and health consequences and develop intervention programme

\section{B. Sample}

For quantitative data collection 471 cases, sample included all patients aged over 18 years old from one stop crisis centre (OSCC) in 3 hospitals of Bangkok Metropolitan Administration which covered areas in city and out city of Bangkok.

For Qualitative method, sample included 20 cases; 10 victims and 10 perpetrators, aged over 18 years old who was residing in Bangkok, Thailand. They were all voluntary. In fact, all these 20 persons used to be a victim and/or a perpetrator but now they are a survival. All of them completely willing shared their violence experiences to the society.

\section{Procedures}

Quantitative data: collected data of all patients from one stop crisis centre (OSCC) in 3 hospitals.

Qualitative data: collected data by in-depth interview at least 2 times/ person from 10 victims and 10 perpetrators, who was residing in Bangkok which covered area in city and out of city.

Subjects who consented to participate in the study were interviewed by researcher with a semi- structured interview at the time of consent. This study was approved by the Ethics Review Committee for Research Involving Human Research Subjects, Health Science Group, Chulalongkorn University.

The researcher clearly explained the purposes and the procedures of the study to the participants. Inform consent of the participants which contains information of confidentiality, free participation, freedom to withdraw, and no use for other purpose.

\section{Measure and Data Analysis}

Quantitative data collection was completed from patient record consists of socio-economic information, forms of violence, causes of violence, health consequence and whether notify the police.

The Semi-structured interview guide was developed by the researcher based on the WHO Multi-country Study on Women's Health and Domestic Violence against Women [10]; consists of 5 issues; Background socio-economic information, Prevalence and characteristics of violence, Risk and protective factors for IPV, Health outcome and other consequences of violence, Opinion about Domestic Violence Victim Protection Act, B.E. 2550, Women's responses to violence/ Way of solution (Male). Descriptive statistics including frequencies and percentages were used for quantitative data. Content analysis were used for qualitative data

\section{RESUlTS}

\section{A. Quantitative}

The study found that there are 471 women victim came to the hospital. In each month, there were admitted 60-90 cases or about $6 \%$ of inpatients to the hospital. In these cases, $63.3 \%$ of perpetrators were married couples / cohabiting, followed by acquaintance/cousins (29.1\%) and stranger (7.6\%) (See Fig. 1).

Perpetrators

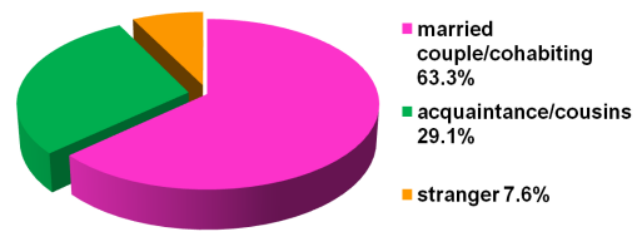

Fig. 1. Type of perpetrator.

Examining the forms of violence revealed that $83 \%$ were physical violence, followed by psychological violence $(9.1 \%)$ sexual violence (5.9\%) and other (1.9\%), (See Fig. 2).

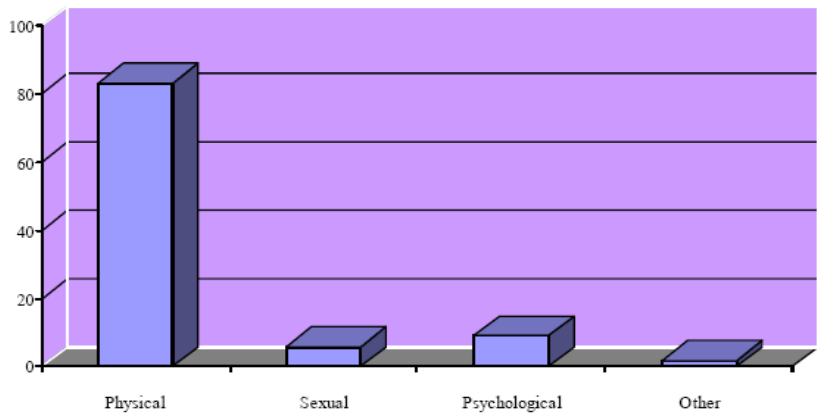

Fig. 2. Diagram for forms of violence.

For times to get violence indicated that more than $50 \%$ of women victim get violence more than 1 time. If focused only married couples and cohabiting found that more than $70 \%$ of women were re-victimization (See Table I) However, it is interesting to note that these cases did not notify the police which reflect that intimate partner violence still private issue and internal family matters in their opinion. Several factors were found to be associated with the occurrence of violence, especially arguing and alcohol drinking of partner. Heavy drinking might contribute directly to an increased risk of violence as the disinhibiting effect it has on cognitive and perceptions.

\section{B. Qualitative}

\section{1) Factors related intimate partner violence}

Both victim and perpetrator said that causes of intimate partner violence stems from individuals and interpersonal determinants. Individual level, for instance, stress, lack of emotional control, lack of anger management, or perpetrator's previous history of aggression, included alcohol 
and drug abuse. In this study found that alcohol drinking of partner associated with the occurrence of violence $(n=15)$. Interpersonal level such as family relations, communication between partner $(n=20)$, and resource management $(n=13)$, Based on current research revealed that when husbands and wives do not have share responsibilities on these issues, wives are at higher risk of violence. In addition, wives or women at greatest risk for physical violence from partner included these with male partners who were unemployed or intermittently employed $(n=3)$. Moreover, lacking of peer and family support was another factor associated with intimate partner violence $(n=8)$.

TABLE I: TIMES TO GET VIOLENCE

\begin{tabular}{|c|c|c|c|c|c|c|c|c|}
\hline \multirow[t]{3}{*}{ Times to get violence } & \multicolumn{8}{|c|}{ Relationship } \\
\hline & \multicolumn{2}{|c|}{ Married/Co-habiting } & \multicolumn{2}{|c|}{ Acquaintance/Cousins } & \multicolumn{2}{|c|}{ Stranger } & \multicolumn{2}{|c|}{ Total } \\
\hline & $n$ & $\%$ & $n$ & $\%$ & $n$ & $\%$ & $n$ & $\%$ \\
\hline First time & 65 & 22.3 & 101 & 75.4 & 34 & 97.1 & 200 & 43.4 \\
\hline More than 1 time & 227 & 77.7 & 33 & 24.6 & 1 & 2.9 & 261 & 56.6 \\
\hline (missing) & (6) & - & (3) & - & (1) & - & (10) & - \\
\hline Total & 292 & 100 & 134 & 100 & 35 & 100 & 461 & 100 \\
\hline
\end{tabular}

\section{2) Consequences}

Intimate partner violence is associated with a wide range of negative health outcomes for women. These range from mild to severe injuries. Intimate partner violence have also been associated with psychiatric problems, including depression, anxiety, phobias, post-traumatic stress disorder, and alcohol and drug abuse as a means of coping with the psychological consequences . Besides, being a victim of violence can also increase an individual's risk of further abuse and of becoming a perpetrator of violence. In addition, the social and economic costs of intimate partner violence are enormous and have ripple effects throughout society. Women may suffer isolation, inability to work, loss of wages, lack of participation in regular activities, and limited to care for themselves and their children.

\section{3) Solutions}

The couples manage or resolve problem by themselves not let other involved. When intimate partner violence happen, household members often hide it to protect the family's name. The victims have to remain in situation of violence in silence and often in isolation.

\section{Intervention Program Development for Reducing Intimate Partner Violence}

From data both Quantitative and Qualitative also documentary study based on social learning theory, feminist theory, structuration theory, and Duluth model; were used to initiate and develop programme intervention. Program should included 5 themes, as follow:

- Abusive and violence behavior

- Consequences and impact of violence

- Non-controlling and non-violent behavior

- Empowerment and Group support

- Communication skills.

The purposes of the programme are; to reduce conflict/ intimate partner violence and to improve relationship functioning among married or cohabiting and to increase positive feeling, goodwill, and commitment to the relationship; details are as follow,

The programme consists of 2 parts. The first part is separated by gender-specific group and the second part is couple focus approach; details as followed;

\section{1) Gender-specific group}

Topic 1 Male: Understanding abusive behavior and social contexts; Let participants analyze how men maintain control and abused in the relationship. Focus on general violence against women as well as identify cultural and social influences that contributes to abusive behavior; Female: Assessing experience with abuse; increasing woman awareness of the dynamics of abuse relationship and reflect on her own experience.

Topic 2 Male: Examining specific acts of abuse as a tactic of control; Let participants explore and analyzes their own use of abusive behavior. Increase the participant's understanding of his abuse as a means of controlling his partner's actions, thoughts, and/or feelings; Female: Impact of abuse and group sharing; increasing woman's awareness of violence affect by examining the harmful, damaging and consequences of intimate partner violence. Group sharing to reflect on her own experience, her own decisions and whether they are increasing her strength, security, and independence.

Topic 3 Male: Health consequences and impact of violence; examining the negative effects of violence and encouraging the participants accept and responsibility for its impact on his partner; Female: Group Support; Group processing for sharing and supporting between women. It is necessary to get support from someone who understands what it is like to live with abuse and will not judge each other for what should do or don't do.

Topic 4 Male: Exploring and practicing non-controlling and non-violent behavior; providing the participants to change abusive behavior by exploring non-controlling and nonviolent ways of relating to women; Female: Coping and Social support; Increasing women awareness of the many different ways that women Providing information that can be used to make decisions related to safety and recovery.

\section{2) Couple focus}

Topic 1 Increasing positive activities; increasing positive feeling, goodwill, and commitment to the relationship.

Topic 2 Communications; learning different ways of communicating feelings and solving problems without being controlling, for instance, practice listening skills. Because of 
Good listening help each spouse to feel understood and supported Intervention programme will be explored in the community for testing the programme.

\section{Discussions}

Intimate partner violence differs from other crime because it happens in the home. It is one of the most difficult crimes to prevent because people generally consider the home is one of the safest places. When Intimate partner violence happens, household members often hide it to protect the family's name. The victims have to remain in situation of violence in silence and often in isolation [4].

Beyond socio-demographic, history of previous abuse, lack of peer and family support, multiple ill-health risk factors, characteristics of male partner are associated with intimate partner violence, Gender power relation factor have been found to be consistently associated with the physical assault of intimate partner. At the societal level, include poverty and social norms that reflect male dominance. At the individual level, it has been demonstrated that those who physically assault their partners are more likely to have been raised in families with patriarchal values and subscribe to patriarchal values [11].

Based on this research, has shown that intimate partner violence is a major public health problems which lead to many immediate and long-term women's health outcomes. In the WHO multi-country study emotional distress was identified through symptoms such as crying easily, inability to enjoy life, fatigue, and thoughts of suicide in the 4 weeks prior to the interview [10]. The health consequences of intimate partner violence are varied, including physical and psychological effects, both in the short term and in the long term. Most victims can have devastating long term psychological effects, influencing and rapically altering a person's entire life [12], [13].

For reduce intimate partner violence, this study suggest that should focus both victim and perpetrator aspect or in other word focus both female and male side; Care and support programmes for victims and prevent batterers from continuing to use violence in their relationships by Exploring and practicing non-controlling and non-violent behavior, especially enhancing communication and increasing positive feeling between partner also teaching and practicing communication skills to resolve conflicts.

Intervention to identify victims of intimate partner violence and prevent batterer from continuing to use violence and also provide effective care and support; will help for protecting health, increase safety, reduce further harm, and breaking cycles of intimate partner violence.

\section{ACKNOWLEDGEMENTS}

This work was partially supported by The 90th Anniversary of Chulalongkorn University Fund (Ratchadaphiseksomphot Endowment Fund)

\section{REFERENCES}

[1] Break the silence, Friend of Women Foundation, Bangkok, 2005.

[2] Fact Sheet: Violence against Women, World Health Organization, November 2009.

[3] Fact Sheet: Violence and Injury Prevention, World Health Organization, 2002.

[4] K. Archavanitkul et al., Intimate Partner Violence and Women's Health in Thailand, Nakhonprathom: IPSR Publication, 2005.

[5] A. R. Roberts and B. Roberts, Ending Intimate Abuse: Practical Guidance and Survival Strategies, New York: Oxford University Press, 2005.

[6] National Statistical Office, "Ministry of information and communication technology," Report of 2006 Reproductive Health Survey, Bangkok, 2006.

[7] A. Sricamsuk, "Domestic violence against pregnant women: A Thai perspective," Doctoral's Dissertation, School of Nursing and Midwifery, Griffith University, 2006.

[8] P. Jaffe et al., "Emotional and physical health problems of battered women," Canadian Journal of Psychiatry, vol. 31, pp. 625-629, 1986.

[9] World Health Organization, "Reducing violence through victim identification, care and support programmes (series of briefing on violence prevention: the evidence)," Geneva, 2009.

[10] World Health Organization, "WHO multi-country study on women's health and domestic violence against women: initial results on prevalence, health outcomes and women's response," Geneva, 2005.

[11] D. Levinson, Family Violence in Cross-Cultural Perspective, Newbury Park, CA: Sage Publications, 1989.

[12] N. J. Pender, Health Promotion in Nursing Practice, $2^{\text {nd }}$ ed. Connecticut: Appleton \& Lange, 1996.

[13] World Health Organization. "Guidelines for medico-legal care for victims of sexual violence," Geneva, 2003, B. Siriphanich, "Caring for the old in a changing society," World Health Forum, vol. 7, pp. 181-184, 1986

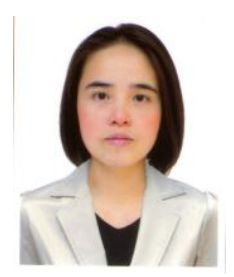

Montakarn Chuemchit was born in Phetchaburi province, Thailand on August 25, 1978. Finished Bachelor of Arts in Journalism and Communication, 1999, Second Class Honors, Thammasat University, Bangkok, Thailand. Master of Arts in Communication Arts, 2002, Very good Thesis entitled "The Victimization of Women in Newspapers and Their Survival", Chualongkorn University, Bangkok, Thailand. In present, Ph.D. Candidate on Public Health Sciences at the College of Public Health Sciences. Chualongkorn University. Bangkok, Thailand. She is a Ph.D. Candidate and researcher at College of Public Health Sciences. Chualongkorn University, Bangkok, Thailand. Her research interest is violence against women, women health, gender, sexuality \& sexual health and elderly health. 